\title{
Association of Common Available Blood cell indices With Rapid Kidney Function Decline in General Population
}

\section{Yichun Cheng}

Tongji Hospital of Tongji Medical College of Huazhong University of Science and Technology

\section{Meian He}

School of publich health, Huazhong university of science and technology

\section{Nanhui Zhang}

Tongji Hospital of Tongji Medical College of Huazhong University of Science and Technology

\section{Gang Xu}

Tongji Hospital of Tongji Medical College of Huazhong University of Science and Technology

Shuwang Ge ( $\nabla$ geshuwang@tjh.tjmu.edu.cn )

Tongji Hospital, Tongji Medical College, Huazhong University of Science and Technology https://orcid.org/0000-0002-5511-0288

\section{Research article}

Keywords: Blood cell indices, kidney function decline, general population, hemoglobin, platelet, monocyte

Posted Date: June 22nd, 2020

DOI: https://doi.org/10.21203/rs.3.rs-35641/v1

License: (c) (1) This work is licensed under a Creative Commons Attribution 4.0 International License. Read Full License 


\section{Abstract}

Background: Blood cell morphology analysis is commonly used in clinic practice. The association of common available blood cell indices with rapid kidney function decline in general population is unknown.

Methods: Participants with complete data of blood cell indices and eGFR $\geq 60 \mathrm{ml} / \mathrm{min} / 1.73 \mathrm{~m}^{2}$ from Dongfeng-Tongji cohort were enrolled. Rapid kidney function decline was defined as a $\geq 25 \%$ decrease in eGFR from baseline. 16 common available blood cell indices were included and logistic regression analysis adjusted for potential confounders was used to assess if these blood cell indices were related to rapid kidney function decline.

Results: A total of 9026 participants were enrolled in our study, 345 (3.8\%) participants experienced a $\geq 25 \%$ eGFR decrease from baseline after 5 years follow-up. High red blood cell count, hemoglobin, hematocrit, monocyte count tended to be related to low kidney function at baseline. After adjustment for a set of potential confounders, low hemoglobin, high platelet count and high monocyte count were significantly associated with rapid kidney function decline.

Conclusions: we presented low hemoglobin, high monocyte and high platelet count as predictors of rapid kidney function decline in general population. Further studies are needed to investigate the underlying mechanism.

\section{Background}

Chronic kidney disease (CKD) is a worldwide health problem with an estimated prevalence of $10.8 \%$ in China [1]. Kidney function is important to monitor kidney disease [2], it decreases with age in general population[3]. However, the rate of kidney function decline differs between individuals. Studies reported that rapid decline of kidney function was associated with cardiovascular events and all-cause mortality in populations not only with impaired renal function but also with normal kidney function [4-6]. Therefore, early detection and management of renal function deterioration is important in the general population.

Blood cell morphology analysis is low-costing and widely available in clinic routine, it can provide information regarding inflammation and hematopoiesis [7]. Inflammatory processes play an important role in the development of kidney damage [8]. A number of studies over more than a decade have noted that white blood cell and its subtypes may be associated with poor outcome in patients with CKD [9-11]. Also, anemia is a known complication of renal insufficiency, presumably due to decreases in erythropoietin production and derangements in iron homeostasis [12]. Low hemoglobin or hematocrit have been proved to be related to poor outcome in patients with CKD and end stage renal disease (ESRD) [13-15]. However, previous studies about these blood cell indices were restricted to western countries, small sample and select group of CKD. The association of blood cell indices and kidney function decline in general population is unknown. 
Therefore, we aimed to investigate the association between common available blood cell indices and rapid kidney function decline in a large group of general population.

\section{Methods}

\section{Study population}

Data in our analysis was derived from the Dongfeng-Tongji (DFTJ) cohort, the details has been described in our previous study [16]. In brief, A total of 27009 retirees was enrolled from Dongfeng Motor Corporation in Hubei Province of central China in 2008. All retirees completed baseline questionnaire, medical examinations and provided blood samples. Follow-up investigations were conducted during from June 2013 to October 2013, with a follow-up rate of $96.2 \%$. Participants without serum creatinine measurements at baseline $(n=452)$ and follow-up $(n=4330)$ were exclude. We excluded participants without complete blood cell indices $(n=6824)$ and other baseline variables $(n=4203)$. We also excluded participants with baseline estimated glomerular filtration rate (eGFR) less than $60 \mathrm{ml} / \mathrm{min} / 1.73 \mathrm{~m}^{2}(\mathrm{n}=$ 2174). Finally, a total of 9026 individuals were included in our study.

\section{Assessment of covariates at baseline}

The socio-demographic characteristics and lifestyles was collected by trained interviewers using epidemiological questionnaire [16]. Physical examination was performed on all participants by physicians, nurses and technicians. Body mass index was calculated as weight (kilogram) divided by height (meter) squared. Blood samples were collected in the morning after an overnight fast. Hematologic testing was performed using a fully automated analyzer CELL-DYN 3700 (Abbott Laboratories. Abbott Park, Illinois). Serum uric acid and creatinine were measured by the Architect ci8200 automatic analyzer (Abbott Laboratories.Abbott Park, Illinois, U.S.A) following the manufacturer's procedures. The serum creatinine measurement was performed with enzymatic method.

\section{Definition of outcome}

The study outcome was rapid kidney function decline, which was defined as eGFR decline greater than $25 \%$ from baseline [17]. eGFR was calculated from serum creatinine, ethnic, gender, and age, using the Chronic Kidney Disease Epidemiology Collaboration (CKD-EPI) equation [18].

\section{Statistical analysis}

Baseline characteristics were presented as proportion, mean \pm SD or median (interquartile range, IQR). Continuous variables were tested using the t test, Wilcoxon rank sum test, ANOVA, or Kruskal-Wallis test, as appropriate. Categorical variables were tested using the chi-squared test. The correlation coefficient between blood cell indices was computed by Pearson correlation methods. Restricted cubic spline was used to model the association of blood cell indices with baseline eGFR. Logistic regression analysis was performed for each blood cell indices in a separate model, which was adjusted with a set of potential 
confounders (age, sex, body mass index, waist, smoking, drinking, hypertension, diabetes, baseline eGFR and uric acid). Indices with a p-value below 0.05 after adjustment for potential confounders were considered included in a backward stepwise logistic regression. For indices with correlation coefficient greater than 0.9 , the indices with the strongest correlation to the rapid eGFR decline was selected. Finally, for blood cell indices identified from backward stepwise logistic regression, the association between these indices and the endpoint were examined using the multivariable-adjusted restricted cubic spline model.

All $P$ values were two tailed, and values 0.05 were considered statistically significant. Analyses were carried out using SPSS (version 25; IBM SPSS, Chicago, IL) and the R software (version 3.6.1; Free Software Foundation).

\section{Result}

Baseline characteristics was displayed in Table 1. The mean age of study population was $62 \pm 7$ years and $43.7 \%$ were male. Of the 9026 participants with complete data, 345 (3.8\%) participants experienced a $\geq 25 \%$ eGFR decrease from baseline. Participants with rapid eGFR decline were more likely to be elder, greater waist circumference, greater proportion of hypertension and diabetes. We also compared the blood cell indices among study populations (Table 2). Mean corpuscular volume and mean corpuscular hemoglobin were significant lower in participants with rapid kidney function decline, whereas platelet count, white blood cell count, neutrophil count, lymphocyte percentage and monocyte count were higher.

The correlation of hematological biomarkers was shown in Figure 1. In general, the biomarkers derived from same blood cell tended to show significant correlation with each other. Among red blood cell parameters, there was a significant positive relationship between hemoglobin and hematocrit, as well as mean corpuscular volume and mean corpuscular hemoglobin. Besides, lymphocyte percentage was negative related to neutrophil percentage.

We analyzed the relationship of hematological biomarkers and kidney function at baseline. Restricted cubic spline plots showed that participants with higher levels of red blood cell count, hemoglobin, hematocrit and monocyte count tended to have worse kidney function at baseline. (Figure 2).

The logistic regression models demonstrated that six blood cell indices derived from red blood cells $(n=4)$, platelets $(n=1)$, white blood cells $(n=1)$ were significant after adjustment for potential confounders (Table 3). Next, four blood cell indices (hemoglobin, mean corpuscular volume, platelet count and monocyte count) were subsequently included in a backward stepwise model (Table 4). In this model, low hemoglobin, high platelet count and high monocyte count were independently associated with the rapid kidney function decline. The fully adjusted restricted cubic spline curves $(95 \% \mathrm{Cl})$ confirmed the association between these three blood cell indices and rapid kidney function decline (Figure 3). Besides, the conventional risk factors of kidney disease, such as age, hypertension, diabetes and hyperuricemia, were also significantly related to rapid kidney function decline in our study. 


\section{Discussion}

In this large prospective cohort study, we investigated relationship of commonly available blood cell indices and rapid kidney function decline in general population. In consistence with study in CKD patients, low hemoglobin was significantly associated with rapid kidney function loss. Besides, we demonstrated several novel associations. Participants with high monocyte and platelet count exhibited high risk of rapid kidney function decline. These observations provide helpful information to slow the kidney function loss in general population.

Anemia is a common complication and well-known risk factor for disease progression in patients with CKD $[15,19,20]$, however, it has not been recognized in general population. In our study, both low hemoglobin and low hematocrit were risk factors for the rapid kidney function loss in general population. Interestingly, we also observed that hemoglobin and hematocrit level increased with a decrease in eGFR at baseline. In a study enrolled 145,865 adults who visited a health center in Korea, Oh et al reported that hemoglobin level was higher in participants with a subtle decline in renal function [21]. The Atherosclerosis Risk in Communities (ARIC) study showed that the peak value of hemoglobin was observed at eGFR of $75-89 \mathrm{~mL} / \mathrm{min} / 1.73 \mathrm{~m}^{2}$ [22]. These data indicated that hemoglobin and hematocrit level increase in population with minor kidney function insufficiency, presumably due to a compensation mechanisms. Moreover, this compensatory increase might slow the rate of kidney function decline in general population.

Our study demonstrated that monocyte count might be a predictor of rapid kidney function decline in general population. Previous studies about the association of monocyte and kidney function were restricted to patients with CKD. Some epidemiologic studies observed that high monocyte count was as associated with low kidney function in patients with CKD [23, 24]. Moreover, Bowe et al. reported a significant association between higher monocyte count and risk of CKD progression to ESRD in a large longitudinal observational cohort [10]. We demonstrated the relationship of high monocyte count and rapid kidney function loss in general population, which indicated that monocyte may participate in kidney damage at early stage. In recent years, studies have proposed a pathogenic role of monocyte/macrophage in kidney disease. Animal experiment proved that monocytes can differentiate into macrophages in kidney and promote inflammation and renal fibrosis [25]. Blockade of monocyte/macrophage related chemokine can reduced recruitment of monocyte and abrogates the development of kidney injury in various animal models, including unilateral ureteral obstruction, adriamycin-induced nephrotic syndrome and diabetic kidney injury [26-28]. More studies are necessary to investigate the mechanism underlying the association of monocytes and kidney injury in future.

This is the first study indicated that platelet count has the ability to predict rapid kidney function decline in general population. Due to its important roles in the hemostasis and thrombosis, platelet was reported to be associated with high incidence of atherosclerotic cardiovascular disease (CVD) [29]. Also, a few studies have observed that high platelet count was associated with high CVD mortality in patients on hemodialysis $[30,31]$. However, the research regarding the relationship of platelet and kidney function 
loss is limited. Our study demonstrated that platelet may also participate in kidney damage. Platelets was anucleate megakaryocyte fragmentation in circulating blood, it can interact with other types of immune cells, including T-cells, neutrophils, and mononuclear phagocytes. These interactions might initiate and exacerbate the inflammation [32]. Therefore, high platelet count could reflect chronic inflammatory status in population with relative normal kidney function. In addition, platelet is correlated with established kidney injury risk factors, such as hypertension, diabetes and metabolic syndrome [33, 34]. These may explain the observed association between high platelet count and rapid kidney function decline in our study.

The main strengths of our study are the prospective design, the relatively large sample size, and adjustment for a number of potential confounders. However, several limitations should be considered in the present study. Firstly, we did not collected data about urinary protein at baseline, thus, we were not able to exclude participants with eGFR $\geq 60 \mathrm{~mL} / \mathrm{min} / 1.73 \mathrm{~m}^{2}$ but abnormal urinary protein levels in our analysis. Secondly, most participants of our study were middle-aged and older Chinese, thus the results may not be generalized to populations of all ages or other ethnicities. Finally, despite including a wide range of potential confounding factors, there may exist confounders either unmeasured or unknown that could explain the rapid kidney function loss seen.

\section{Conclusions}

In conclusion, our study demonstrated some common available blood cell indices, such as hemoglobin, platelet and monocyte, were significantly associated with rapid kidney function decline in general population. Efforts to understand the role of these blood cells in kidney damage may have the potential to decrease the rate of kidney function loss.

\section{Abbreviations}

CKD: chronic kidney disease; DFTJ: dongfeng-tongji; ESRD: end stage renal disease; eGFR: estimated glomerular filtration rate; CKD-EPI: chronic kidney disease epidemiology collaboration; IQR: interquartile range; ARIC: atherosclerosis risk in communities; CVD: cardiovascular disease.

\section{Declarations}

\section{Ethics approval and consent to participate}

This study was approved by the Medical Ethics Committee of the School of Public Health, Tongji Medical College, Huazhong University of Science and Technology and Dongfeng General Hospital, DMC. All procedures performed in studies involving human participants were in accordance with the 1964 Helsinki declaration and its later amendments or comparable ethical standards. All participants provided written informed consent. 
Not applicable

\section{Availability of data and materials}

The datasets used and analyzed during the current study are available from the corresponding author on reasonable request

\section{Competing interests}

Authors have disclosed no conflicts of interest

\section{Funding}

This work was financially supported by the International (regional) cooperation and exchange projects, (NSFC-DFG, Grant No. 81761138041); National Natural Science Foundation of China (Grants 81570667, 81470948, 81670633); Major Research Plan of the National Natural Science Foundation of China (Grant No. 91742204); The National Key R\&D Program of China (Grants 2018YFC1314003-1®2015BAI12B07)区 and National key research and development program $\otimes$ Grant 2016YFC0906103凶. The funders played no role in the design of the study, collection, analysis, and interpretation of data, or in writing the manuscript.

\section{Author contributions}

GX and YC conceived and designed the study, MH and NZ collected the data; YC and SG analyzed the data and wrote the first draft of the paper. All authors read and approved the final manuscript.

\section{Acknowledgements}

We give our sincere gratitude to Prof. Wu Tangchun, who designed and conducted DFTJ-cohort study. We also thank all study subjects for participating in the present DFTJ-cohort study as well as all volunteers for assisting in collecting the samples and data.

\section{Reference}

1. Wang J, Zhang L, Tang SC, Kashihara N, Kim YS, Togtokh A, Yang CW, Zhao MH, North ISN, East Asia Regional B. Disease burden and challenges of chronic kidney disease in North and East Asia. Kidney Int 2018, 94(1):22-25.

2. KDIGO CKD Work Group. KDIGO 2012 clinical practice guideline for the evaluation and management of chronic kidney disease. Kidney Int Suppl 2013, 3:1-150.

3. Epstein M. Aging and the kidney. J Am Soc Nephrol 1996, 7:1106-1122.

4. Al-Aly Z, Zeringue A, Fu J, Rauchman MI, McDonald JR, El-Achkar TM, Balasubramanian S, Nurutdinova D, Xian H, Stroupe K et al. Rate of kidney function decline associates with mortality. J Am Soc Nephrol 2010, 21(11):1961-1969. 
5. Naimark DMJ, Grams ME, Matsushita K, Black C, Drion I, Fox CS, Inker LA, Ishani A, Jee SH, Kitamura A et al. Past Decline Versus Current eGFR and Subsequent Mortality Risk. J Am Soc Nephrol 2016, 27(8):2456-2466.

6. Guo Y, Cui L, Ye P, Li J, Wu S, Luo Y. Change of Kidney Function Is Associated With All-Cause Mortality and Cardiovascular Diseases: Results From the Kailuan Study. J Am Heart Assoc 2018, 7(21):e010596.

7. Vis JY, Huisman A. Verification and quality control of routine hematology analyzers. Int J Lab Hematol 2016, 38 Suppl 1:100-109.

8. Ernandez T, Mayadas TN. The Changing Landscape of Renal Inflammation. Trends Mol Med 2016, 22(2):151-163.

9. Fried L, Solomon C, Shlipak M, Seliger S, Stehman-Breen C, Bleyer AJ, Chaves P, Furberg C, Kuller L, Newman A. Inflammatory and prothrombotic markers and the progression of renal disease in elderly individuals. J Am Soc Nephrol 2004, 15(12):3184-3191.

10. Bowe B, Xie Y, Xian H, Li T, Al-Aly Z. Association between Monocyte Count and Risk of Incident CKD and Progression to ESRD. Clin J Am Soc Nephrol 2017, 12(4):603-613.

11. Fan F, Jia J, Li J, Huo Y, Zhang Y. White blood cell count predicts the odds of kidney function decline in a Chinese community-based population. BMC Nephrol 2017, 18(1):190.

12. Rossert J, Froissart M. Role of anemia in progression of chronic kidney disease. Semin Nephrol 2006, 26(4):283-289.

13. Strippoli GF, Craig JC, Manno C, Schena FP. Hemoglobin targets for the anemia of chronic kidney disease: a meta-analysis of randomized, controlled trials. J Am Soc Nephrol 2004, 15(12):3154-3165.

14. Bansal N, Tighiouart H, Weiner D, Griffith J, Vlagopoulos P, Salem D, Levin A, Sarnak MJ. Anemia as a risk factor for kidney function decline in individuals with heart failure. Am J Cardiol 2007, 99(8):1137-1142.

15. Jha V, Yi S-W, Moon SJ, Yi J-J. Low-normal hemoglobin levels and anemia are associated with increased risk of end-stage renal disease in general populations: A prospective cohort study. Plos One 2019, 14(4):e0215920.

16. Wang F, Zhu J, Yao P, Li X, He M, Liu Y, Yuan J, Chen W, Zhou L, Min X et al. Cohort Profile: the Dongfeng-Tongji cohort study of retired workers. Int J Epidemiol 2013, 42(3):731-740.

17. Coresh J, Turin TC, Matsushita K, Sang Y, Ballew SH, Appel LJ, Arima H, Chadban SJ, Cirillo M, Djurdjev $O$ et al. Decline in estimated glomerular filtration rate and subsequent risk of end-stage renal disease and mortality. JAMA 2014, 311(24):2518-2531.

18. Levey AS, Stevens LA, Schmid CH, Zhang YL, Castrolll AF, Feldman HI, Kusek JW, Eggers P, Lente FV, Greene T et al. CKD-EPI (Chronic Kidney Disease Epidemiology Collaboration): A new equation to estimate glomerular filtration rate. Annals of internal medicine 2009, 150:604-612.

19. Iseki K, Ikemiya Y, Iseki C, Takishita S. Haematocrit and the risk of developing end-stage renal disease. Nephrol Dial Transplant 2003, 18(5):899-905. 
20. Astor BC, Muntner P, Levin A, Eustace JA, Coresh J. Association of kidney function with anemia the third National Health and Nutrition Examination Survey (1988-1994). Arch Intern Med 2002, 162:1401-1408.

21. Oh SW, Baek SH, Kim YC, Goo HS, Chin HJ, Na KY, Chae DW, Kim S. Higher hemoglobin level is associated with subtle declines in renal function and presence of cardiorenal risk factors in early CKD stages. Nephrol Dial Transplant 2012, 27(1):267-275.

22. Astor BC, Arnett DK, Brown A, Coresh J. Association of kidney function and hemoglobin with left ventricular morphology among African Americans: the Atherosclerosis Risk in Communities (ARIC) study. Am J Kidney Dis 2004, 43(5):836-845.

23. Evangelopoulos AA, Vallianou NG, Bountziouka V, Katsagoni C, Bathrellou E, Vogiatzakis ED, Bonou MS, Barbetseas J, Avgerinos PC, Panagiotakos DB. Association between serum cystatin C, monocytes and other inflammatory markers. Intern Med J 2012, 42:517-522.

24. Ganda A, Magnusson M, Yvan-Charvet L, Hedblad B, Engstrom G, Ai D, Wang TJ, Gerszten RE, Melander O, Tall AR. Mild renal dysfunction and metabolites tied to low HDL cholesterol are associated with monocytosis and atherosclerosis. Circulation 2013, 127(9):988-996.

25. Ricardo SD, van Goor H, Eddy AA. Macrophage diversity in renal injury and repair. J Clin Invest 2008, 118(11):3522-3530.

26. Kang YS, Lee MH, Song HK, Ko GJ, Kwon OS, Lim TK, Kim SH, Han SY, Han KH, Lee JE et al. CCR2 antagonism improves insulin resistance, lipid metabolism, and diabetic nephropathy in type 2 diabetic mice. Kidney Int 2010, 78(9):883-894.

27. Anders H-J, Vielhauer V, Frink M, Linde Y, Cohen CD, Blattner SM, Kretzler M, Strutz F, Mack M, Gröne $\mathrm{H}-\mathrm{J}$ et al. A chemokine receptor CCR-1 antagonist reduces renal fibrosis after unilateral ureter ligation. J Clin Invest 2002, 109(2):251-259.

28. Anders HJ, Ninichuk V, Schlondorff D. Progression of kidney disease: blocking leukocyte recruitment with chemokine receptor CCR1 antagonists. Kidney Int 2006, 69(1):29-32.

29. Semple JW, Italiano JE, Jr., Freedman J. Platelets and the immune continuum. Nat Rev Immunol 2011, 11(4):264-274.

30. Molnar MZ, Streja E, Kovesdy CP, Budoff MJ, Nissenson AR, Krishnan M, Anker SD, Norris KC, Fonarow GC, Kalantar-Zadeh K: High platelet count as a link between renal cachexia and cardiovascular mortality in end-stage renal disease patients. Am J Clin Nutr 2011, 94(3):945-954.

31. Peng F, Li Z, Yi C, Guo Q, Yang R, Long H, Huang F, Yu X, Yang X. Platelet index levels and cardiovascular mortality in incident peritoneal dialysis patients: a cohort study. Platelets 2017 , 28(6):576-584.

32. Gawaz M, Langer H, May AE. Platelets in inflammation and atherogenesis. J Clin Invest 2005, 115(12):3378-3384.

33. Taniguchi A, Fukushima M, Seino Y, Sakai M, Yoshii S, Nagasaka S, Yamauchi I, Okumura T, Nin K, Tokuyama $\mathrm{K}$ et al. Platelet count is independently associated with insulin resistance in non-obese Japanese type 2 diabetic patients. Metabolism 2003, 52(10):1246-1249. 
34. Tayefi M, Hassanian SM, Maftouh M, Moohebati M, Bahrami A, MohammadReza S, Parizadeh, Mahdizadeh A, Ghazizadeh H, Bazeli J et al. Relationship between platelet count and platelet width distribution and serum uric acid concentrations in patients with untreated essential hypertension. BioFactors 2018, 44:532-538.

\section{Tables}

Table 1. Baseline characteristics of study population

\begin{tabular}{|llll|}
\hline Characteristics & eGFR decline<25\% & eGFR decline $>25 \%$ & P value \\
\hline Number & 8681 & 345 & \\
\hline Age (year) & $63 \pm 7$ & $64 \pm 8$ & 0.001 \\
\hline Sex (male, \%) & 44.9 & 45.9 & 0.698 \\
\hline BMI $\left(\mathrm{kg} / \mathrm{m}^{2}\right)$ & $24 \pm 3$ & $25 \pm 3$ & $<0.001$ \\
\hline Waist $(\mathrm{cm})$ & $81 \pm 9$ & $84 \pm 9$ & $<0.001$ \\
\hline Smoking (never, past, current, \%) & $(70.9,11.2,17.9)$ & $(69.2,13.4,17.4)$ & 0.461 \\
\hline Drinking (never, past, current, \%)) & $(72.8,5.5,21.7)$ & $(75.9,7.0,17.2)$ & 0.089 \\
\hline Hypertension $(\%)$ & 34.8 & 48.3 & $<0.001$ \\
\hline Diabetes $(\%)$ & 11.1 & 21.2 & $<0.001$ \\
\hline eGFR $\left(\mathrm{ml} / \mathrm{min} / 1.73 \mathrm{~m}^{2}\right)$ & $82 \pm 12$ & $86 \pm 13$ & $<0.001$ \\
\hline Urea acid $(\mu \mathrm{mol} / \mathrm{L})$ & $293 \pm 74$ & $301 \pm 80$ & $\mathbf{0 . 0 4 3}$ \\
\hline
\end{tabular}

Continuous variables are presented as mean \pm standard deviation. Categorical variables are presented as percentage.

Table 2. Comparison of blood cell indices stratified by kidney function decline rate. 


\begin{tabular}{|llll|}
\hline & $\begin{array}{l}\text { eGFR } \\
\text { decline }<25 \%\end{array}$ & $\begin{array}{l}\text { eGFR } \\
\text { decline }>25 \%\end{array}$ & $\begin{array}{l}\text { value } \\
\text { Red blood cell }\left(10^{12} / \mathrm{L}\right)\end{array}$ \\
\hline Hemoglobin $(\mathrm{g} / \mathrm{L})$ & $4.6 \pm 0.4$ & $4.6 \pm 0.4$ & 0.933 \\
\hline Hematocrit $(\%)$ & $136 \pm 13$ & $135 \pm 13$ & 0.061 \\
\hline Mean corpuscular volume (fL) & $41 \pm 4$ & $41 \pm 4$ & 0.074 \\
\hline Mean corpuscular hemoglobin $(\mathrm{pg})$ & $90 \pm 5$ & $89 \pm 6$ & 0.002 \\
\hline $\begin{array}{l}\text { Mean corpuscular hemoglobin concentration } \\
\text { (g/L) }\end{array}$ & $30 \pm 2$ & $29 \pm 2$ & 0.005 \\
\hline Platelet count $\left(10^{9} / \mathrm{L}\right)$ & $328 \pm 8$ & $328 \pm 8$ & 0.378 \\
\hline Plateletcrit $(\%)$ & $182 \pm 47$ & $190 \pm 52$ & 0.008 \\
\hline Mean platelet volume $(\mathrm{fL})$ & $16.5 \pm 4.1$ & $16.8 \pm 4.1$ & 0.085 \\
\hline White blood cell count $\left(10^{9} / \mathrm{L}\right)$ & $9.2 \pm 1.8$ & $9.1 \pm 1.6$ & 0.088 \\
\hline Neutrophil count $\left(10^{9} / \mathrm{L}\right)$ & $6.0 \pm 1.5$ & $6.2 \pm 1.5$ & 0.002 \\
\hline Neutrophil percentage $(\%)$ & $3.4 \pm 1.1$ & $3.6 \pm 1.1$ & 0.002 \\
\hline Lymphocyte count $\left(10^{9} / \mathrm{L}\right)$ & $56.0 \pm 9.0$ & $56.8 \pm 8.4$ & 0.128 \\
\hline Lymphocyte percentage $(\%)$ & $2.0 \pm 0.6$ & $2.0 \pm 0.6$ & 0.406 \\
\hline Monocyte count $\left(10^{9} / \mathrm{L}\right)$ & $33.2 \pm 8.4$ & $32.2 \pm 7.9$ & $\mathbf{0 . 0 3 2}$ \\
\hline Monocyte percentage $(\%)$ & $0.42 \pm 0.13$ & $0.44 \pm 0.13$ & $\mathbf{0 . 0 0 3}$ \\
\hline
\end{tabular}

Data are expressed as mean \pm standard deviation.

Table 3. The logistic regression analysis of the association between hematological biomarkers and rapid kidney function decline 


\begin{tabular}{|lll|}
\hline & OR $(95 \% \mathrm{Cl})$ & $P$ value \\
\hline Red blood cell $\left(10^{12} / \mathrm{L}\right)$ & $0.90(0.66,1.23)$ & 0.500 \\
\hline Hemoglobin $(\mathrm{g} / \mathrm{L})$ & $0.99(0.98,1.00)$ & 0.008 \\
\hline Hematocrit $(\%)$ & $0.95(0.92,0.99)$ & 0.011 \\
\hline Mean corpuscular volume $(\mathrm{fL})$ & $0.97(0.95,1.00)$ & $\mathbf{0 . 0 1 7}$ \\
\hline Mean corpuscular hemoglobin $(\mathrm{pg})$ & $0.93(0.88,0.99)$ & $\mathbf{0 . 0 2 1}$ \\
\hline Mean corpuscular hemoglobin concentration $(\mathrm{g} / \mathrm{L})$ & $0.99(0.98,1.01)$ & 0.391 \\
\hline Platelet count $\left(10^{9} / \mathrm{L}\right)$ & $1.00(1.00,1.01)$ & 0.007 \\
\hline Plateletcrit $(\%)$ & $1.02(0.99,1.05)$ & 0.154 \\
\hline Mean platelet volume $(\mathrm{fL})$ & $0.95(0.89,1.01)$ & 0.097 \\
\hline White blood cell count $\left(10^{9} / \mathrm{L}\right)$ & $1.07(0.99,1.15)$ & 0.094 \\
\hline Neutrophil count $\left(10^{9} / \mathrm{L}\right)$ & $1.07(0.98,1.18)$ & 0.147 \\
\hline Neutrophil percentage $(\%)$ & $1.00(0.99,1.02)$ & 0.629 \\
\hline Lymphocyte count $\left(10^{9} / \mathrm{L}\right)$ & $1.03(0.87,1.23)$ & 0.731 \\
\hline Lymphocyte percentage $(\%)$ & $0.99(0.98,1.01)$ & 0.212 \\
\hline Monocyte count $\left(10^{9} / \mathrm{L}\right)$ & $2.53(1.11,5.78)$ & $\mathbf{0}) .027$ \\
\hline Monocyte percentage $(\%)$ & $1.04(0.98,1.11)$ & 0.204 \\
\hline
\end{tabular}

The results of logistic regression were adjusted for potential confounders (age, sex, body mass index, waist, mean blood pressure, hypertension, diabetes, baseline eGFR and urea acid). OR, odds ratio; $95 \% \mathrm{Cl}$, $95 \%$ confidence interval.

Table 4. Backward logistic regression analysis of the association between hematological biomarkers and rapid kidney function decline 


\begin{tabular}{|c|c|c|}
\hline \multicolumn{2}{|l|}{ OR $(95 \% \mathrm{Cl})$} & $P$ value \\
\hline Age (year) & $1.05(1.03,1.07)$ & $<0.001$ \\
\hline Sex (male) & $1.09(0.77,1.54)$ & 0.649 \\
\hline $\mathrm{BMI}\left(\mathrm{kg} / \mathrm{m}^{2}\right)$ & $1.05(0.99,1.1)$ & 0.101 \\
\hline Waist (cm) & $1.01(0.99,1.03)$ & 0.331 \\
\hline \multicolumn{3}{|l|}{ Smoking } \\
\hline never & reference & \\
\hline past & $0.91(0.63,1.31)$ & 0.606 \\
\hline current & $1.08(0.72,1.63)$ & 0.702 \\
\hline \multicolumn{3}{|l|}{ Drinking } \\
\hline never & reference & \\
\hline past & $1.37(0.98,1.91)$ & 0.066 \\
\hline current & $1.31(0.79,2.17)$ & 0.296 \\
\hline Hypertension & $1.40(1.11,1.78)$ & 0.005 \\
\hline Diabetes & $1.71(1.29,2.27)$ & $<0.001$ \\
\hline Baseline eGFR (ml/min/1.73m²) & $1.05(1.04,1.06)$ & $<0.001$ \\
\hline Urea acid $(\mu \mathrm{mol} / \mathrm{L})$ & $1.00(1.00,1.00)$ & 0.022 \\
\hline Hemoglobin (g/L) & $0.99(0.97,1.00)$ & 0.006 \\
\hline Platelet count $\left(10^{9} / \mathrm{L}\right)$ & $1.00(1.00,1.01)$ & 0.034 \\
\hline Monocyte count $\left(10^{9} / \mathrm{L}\right)$ & $2.39(1.03,5.56)$ & 0.044 \\
\hline
\end{tabular}

BMI, body mass index; eGFR, estimated glomerular filtration rate; OR, odds ratio; $95 \% \mathrm{Cl}, 95 \%$ confidence interval.

\section{Figures}


$\begin{array}{lllllllllllll}\text { RBC HGB HCT MCV MCH MCHC PLT } & \text { PCT } & \text { MPV } & \text { WBC } & \text { N } & \text { N } \% & \text { L } & \text { L } \% & \text { MNC } & \text { MNC } \%\end{array}$

\begin{tabular}{|c|c|c|c|c|c|c|c|c|c|c|c|c|c|c|c|c|}
\hline RBC & 100 & 0.78 & 0.83 & -0.30 & -0.26 & -0.04 & 0.00 & -0.02 & -0.03 & 0.25 & 0.21 & 0.07 & 0.12 & -0.11 & 0.27 & 0.08 \\
\hline HGB & 0.78 & 1.00 & 0.97 & 0.32 & 0.40 & 0.37 & -0.10 & -0.15 & -0.07 & 0.24 & 0.19 & 0.03 & 0.14 & -0.07 & 0.30 & 0.13 \\
\hline HCT & 0.83 & 0.97 & 1,00 & 0.27 & 0.27 & 0.14 & -0.09 & -0.13 & -0.06 & 0.25 & 0.20 & 0.04 & 0.14 & -0.08 & 0.31 & 0.13 \\
\hline MCV & -0.30 & 0.32 & 0.27 & 100 & 0.93 & 0.31 & -0.17 & -0.21 & -0.04 & 0.00 & -0.03 & -0.06 & 0.04 & 0.05 & 0.07 & 0.09 \\
\hline МСH & -0.26 & 0.40 & 0.27 & 0.93 & 1,60 & 0.63 & -0.15 & -0.21 & -0.06 & 0.01 & -0.02 & -0.05 & 0.04 & 0.04 & 0.08 & 0.08 \\
\hline МСНС & -0.04 & 0.37 & 0.14 & 0.31 & 0.63 & 1.00 & -0.05 & -0.12 & -0.08 & 0.03 & 0.02 & 0.00 & 0.02 & 0.00 & 0.04 & 0.02 \\
\hline PLT & 0.00 & -0.10 & -0.09 & -0.17 & -0.15 & -0.05 & 1.00 & 0.76 & -0.40 & 0.30 & 0.24 & 0.03 & 0.23 & 0.00 & 0.13 & -0.14 \\
\hline PCT & -0.02 & -0.15 & -0.13 & -0.21 & -0.21 & -0.12 & 0.76 & 100 & 0.27 & 0.29 & 0.24 & 0.05 & 0.21 & -0.03 & 0.11 & -0.15 \\
\hline MPV & -0.03 & -0.07 & -0.06 & -0.04 & -0.06 & -0.08 & -0.40 & 0.27 & 1.00 & -0.04 & -0.02 & 0.03 & -0.05 & -0.03 & -0.03 & 0.00 \\
\hline WBC & 0.25 & 0.24 & 0.25 & 0.00 & 0.01 & 0.03 & 0.30 & 0.29 & -0.04 & 1,00 & 0.88 & 0.26 & 0.58 & -0.23 & 0.62 & -0.20 \\
\hline $\mathbf{N}$ & 0.21 & 0.19 & 0.20 & -0.03 & -0.02 & 0.02 & 0.24 & 0.24 & -0.02 & 0.88 & 1.00 & 0.67 & 0.15 & -0.62 & 0.47 & -0.26 \\
\hline $\mathrm{N} \%$ & 0.07 & 0.03 & 0.04 & -0.06 & -0.05 & 0.00 & 0.03 & 0.05 & 0.03 & 0.26 & 0.67 & 1.00 & -0.56 & -0.94 & 0.01 & -0.25 \\
\hline L & 0.12 & 0.14 & 0.14 & 0.04 & 0.04 & 0.02 & 0.23 & 0.21 & -0.05 & 0.58 & 0.15 & -0.56 & 1.00 & 0.63 & 0.36 & -0.13 \\
\hline$L \%$ & -0.11 & -0.07 & -0.08 & 0.05 & 0.04 & 0.00 & 0.00 & -0.03 & -0.03 & -0.23 & -0.62 & $-0,94$ & 0.63 & 1,00 & -0.15 & 0.03 \\
\hline MNC & 0.27 & 0.30 & 0.31 & 0.07 & 0.08 & 0.04 & 0.13 & 0.11 & -0.03 & 0.62 & 0.47 & 0.01 & 0.36 & -0.15 & 1.00 & 0.62 \\
\hline $\mathrm{MNC} \%$ & 0.08 & 0.13 & 0.13 & 0.09 & 0.08 & 0.02 & -0.14 & -0.15 & 0.00 & -0.20 & -0.26 & -0.25 & -0.13 & 0.03 & 0.62 & 1.00 \\
\hline
\end{tabular}

\section{Figure 1}

Heatmap of correlations between hematological biomarkers. Red indicates a positive correlation while blue indicates a negative correlation. $\mathrm{RBC}$, red blood cell; $\mathrm{Hb}$, hemoglobin; $\mathrm{HCT}$, hematocrit; $\mathrm{MCV}$, mean corpuscular volume; $\mathrm{MCH}$, mean corpuscular hemoglobin; $\mathrm{MCHC}$, mean corpuscular hemoglobin concentration; PLT, platelet count; PCT, plateletcrit; MPV, mean platelet volume; WBC, white blood cell count; $\mathrm{N}$, neutrophil count; $\mathrm{N} \%$, neutrophil percentage; L, lymphocyte count; $\mathrm{L} \%$, lymphocyte percentage; MNC, monocyte count; MNC\%, monocyte percentage. 

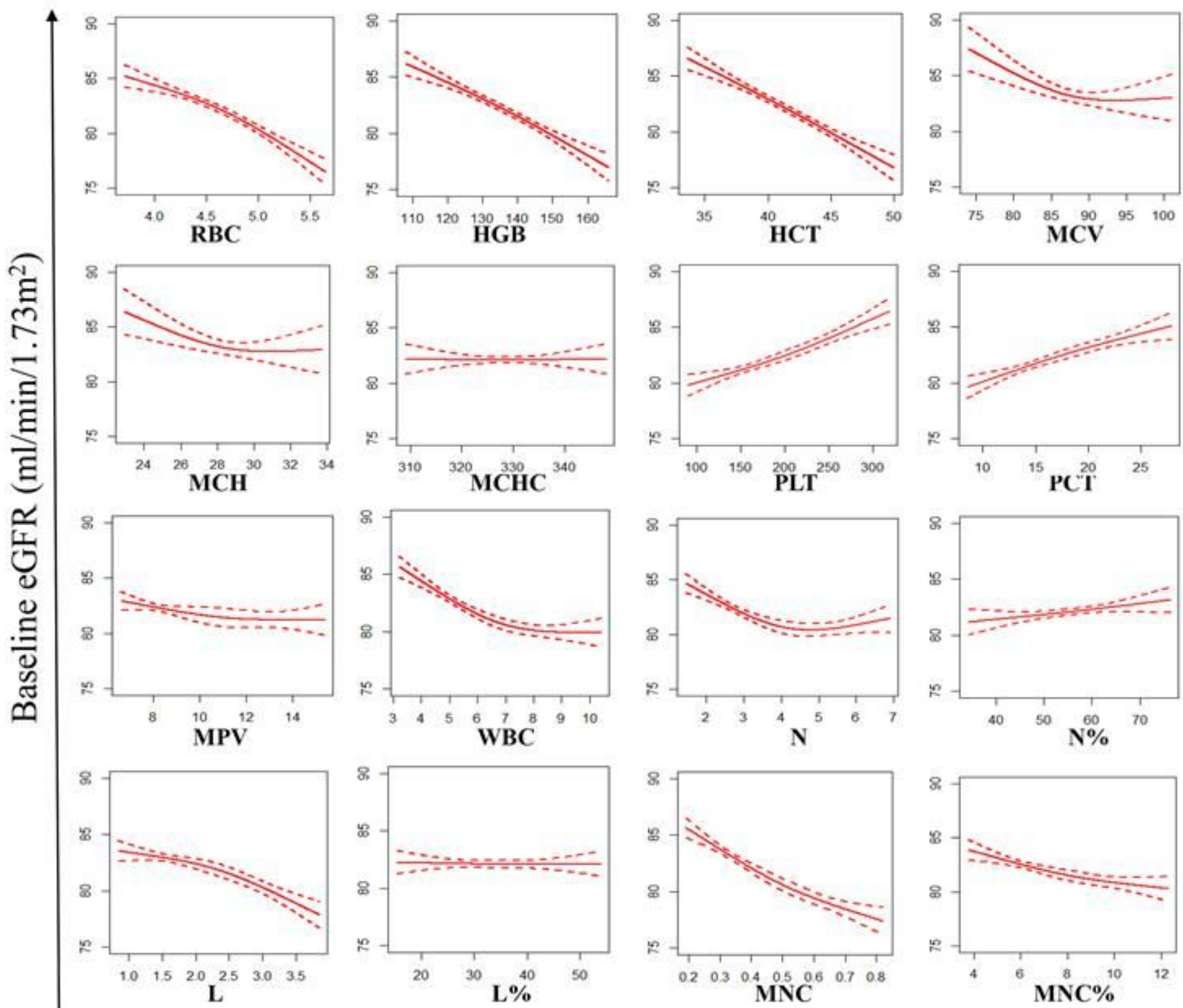

\section{Blood cell indices}

Figure 2

Restricted Cubic spline of baseline kidney function decline and blood cell indeices. Dot line indicate 95\% confidence intervals. RBC, red blood cell; $\mathrm{Hb}$, hemoglobin; $\mathrm{HCT}$, hematocrit; $\mathrm{MCV}$, mean corpuscular volume; $\mathrm{MCH}$, mean corpuscular hemoglobin; $\mathrm{MCHC}$, mean corpuscular hemoglobin concentration; PLT, platelet count; PCT, plateletcrit; MPV, mean platelet volume; WBC, white blood cell count; N, neutrophil count; $N \%$, neutrophil percentage; $L$, lymphocyte count; $L \%$, lymphocyte percentage; $M N C$, monocyte count; $\mathrm{MNC} \%$, monocyte percentage. 

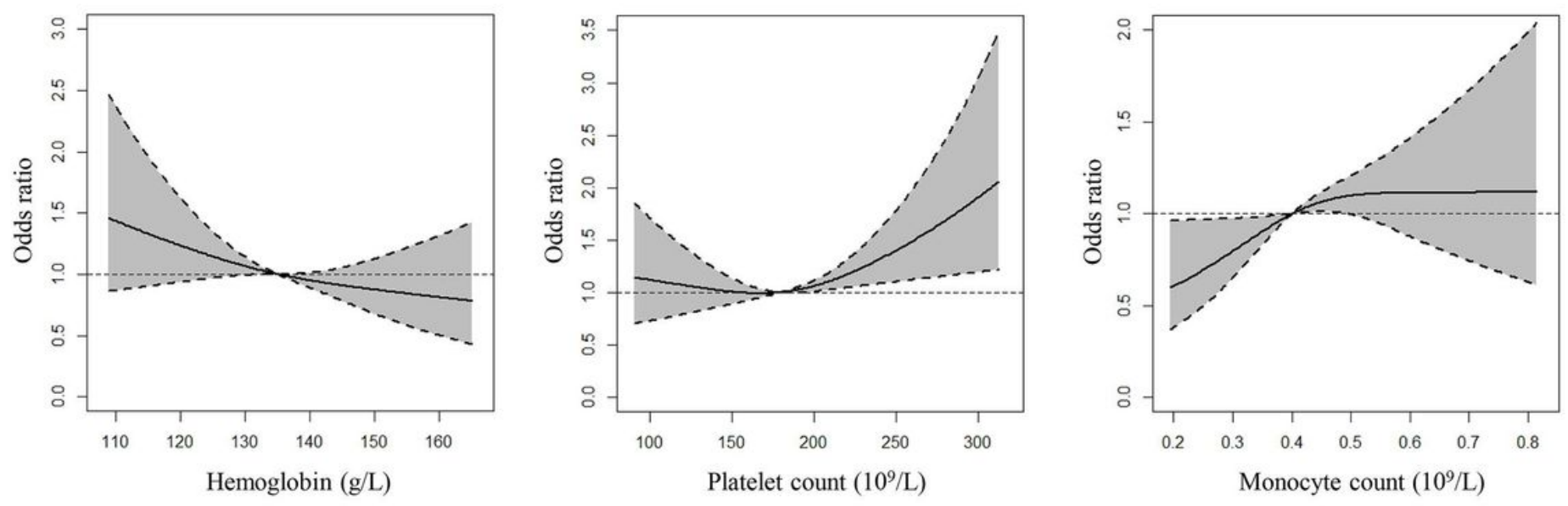

Figure 3

Restricted Cubic spline analyses of risk of rapid kidney function decline by hemoglobin, platelet count, monocyte count. Tinted bands indicate $95 \%$ confidence intervals. 